\title{
ИССЛЕДОВАНИЕ СТРУКТУРЫ СОЕДИНЕНИЙ ОРГАНИЧЕСКИХ ОСНОВАНИЙ ПЕРВИЧНЫХ КАМЕННОУГОЛЬНЫХ СМОЛ
}

\author{
(Представил Н. Клесмент)
}

Цель работы - исследование структуры соединений органических оснований первичных смол термодеструкции каменного угля группы Г6, полученных в условиях, исключающих высокотемпературный пиролиз.

Сведения о структуре соединений органических оснований дополнят наши представления о строении органической массы ископаемых топлив, о формах азота в последней и характере преобразований растительного материала в ходе формирования угля. Кроме того, установление структуры азоторганических соединений позволит сделать предварительный термодинамический и кинетический расчет их высокотемпературных превращений для прогнозирования состава вторичных смол, что веесьма необходимо в целях оптимизации процесса пиролиза.

Схема установки для получения первичной смолы приведена в [']. Тонкий слой коксуемой загрузки (10 мм), высокая равномерность нагрева, система отвода парогазовых продуктов практически исключали их вторичный пиролиз. Смола подвергалась групповому анализу [2]. Органические основания выделяли 10\%-ным водным раствором серной кислоты, насыщенной сульфатом натрия. Выход - 1,3 мас. \% (от смолы).

На первом этапе исследования считалось целесообразным подробно изучить органические основания методами ИК-, УФ- и ${ }^{1} \mathrm{H}-Я М$ М. спектроскопии, хромато-масс-спектрометрии, провести их элементный и функциональный анализы и определить молекулярные массы. Обобщение полученных данных позволило охарактеризовать изучаемые азоторганические основания как сложную смесь соединений различных классов гидроароматической или гидрогетероциклической природы, некоторые из которых замещены кислородными группами (фенольными, хиноидными, кетонными, спиртовыми, простыми эфирными) и короткими алкильными цепочками. Существенную роль в азоторганических соединениях играют пиридиновые, пиримидиновые и пиррольные кольца. Циклические амины - первичные и амиды, наиболее вероятно, вторичные.

Таким образом, термины «органические основания» либо «азотсодержащие соединения» являются условными.

Полученные результаты поставили задачу выбора метода предварительного разделения исходных органических оснований на ряд более простых фракций, так как только в этом случае возможно получение наиболее полной информации о структуре соединений столь сложной смеси. 


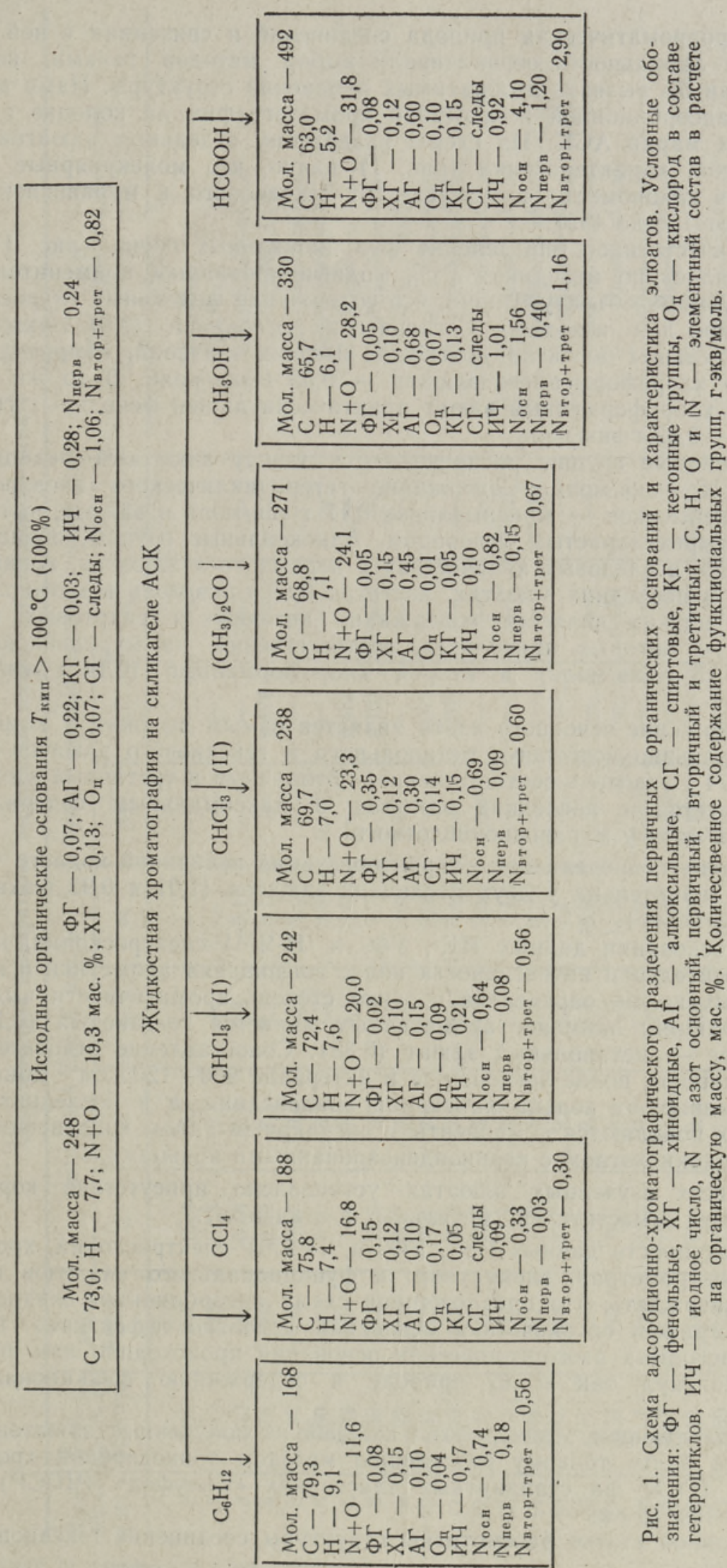


Гидроароматическая природа соединений и связанная с ней повышенная лабильность ограничивали выбор методов такими, которые не могли бы вызвать необратимых изменений структуры. Нами выбран метод адсорбционной жидкостной хроматографии на колонке с силикагелем марки АСК. Из схемы разделения отдельных элюатов и их подробной характеристики (рис. 1) видно, что молекулярные массь: элюатов закономерно возрастают от гексанового к муравьинокислотному (от 168 до 492 ).

Количественное определение функциональных групп (рис. 1) осуществлялось по методикам $\left[{ }^{3-6}\right]$, модифицированным применительно к исследуемому объекту. Видно, что содержание фенольных гидроксилов, невысокое для исходных органических оснований $(0,07$ г-экв/моль), для отдельных элюатов достигает высоких значений, например, для второго хлороформенного элюата $-0,35$ г-экв/моль. В то же время первый хлороформенный элюат практически лишен фенольных гидроксилов - 0,02 г-экв/моль.

Хиноидные группы распределяются между элюатами равномерно: $0,10-0,15$ г-экв/моль. Содержание гетероциклического кислорода в целом невысокое - максимальное 0,17 г-экв/моль в элюате, вытеснен ном четыреххлористым углеродом. Алкоксильные группы, обнаруженные лишь в следовых количествах в первых трех элюатах, концентрируются в последних элюатах, достигая 0,68 г-экв/моль в метанольном. Весьма низким является содержание кетонных и спиртовых групп, максимум которых приходится, соответственно, на муравьинокислотный $(0,15$ г-экв/моль) и второй хлороформенный $(0,14$ г-экв/моль $)$ элюаты.

Содержание основного азота является самым высоким у компонентов муравьинокислотного, метанольного и гексанового элюатов $(4,10$; 1,$56 ; 0,74$ г-экв/моль соответственно). Вторичный и третичный азот концентрируется в последних элюатах с максимальным содержанием 2,9 г-экв/моль у муравьинокислотного.

Степень непредельности, характеризуемая величиной иодного числа, весьма значительна у двух последних элюатов (1,01 и 0,92 г-экв/моль соответственно).

На основании данных ИК-, УФ- и 'Н-ЯМР-спектроскопии, исходя из относительной интенсивности полос поглощения ароматики и гидрированных колец, определена средняя степень ароматичности выделенных фракций: наименее ароматичным является гексановый $(0,10)$, а наиболее - метанольный элюат $(0,38)$. Сопоставление относительной интенсивности полос поглощения в интервале $900-1200 \mathrm{~cm}^{-1}$ показало, что доминируют кольца линеарной конденсации, а в последних трех элюатах появляются компоненты с ангулярным типом конденсации и в муравьинокислотном с периконденсированными кольцами.

Во всех изученных элюатах установлено присутствие коротких алкильных заместителей (метильных и этильных).

Совокупность данных ИК-, УФ- и 'Н-ЯМР-спектроскопии, хроматомасс-спектрометрии, элементного и функционального анализов позволяет утверждать, что предложенная схема адсорбционной жидкостной хроматографии органических оснований довольно эффективна. Разделение исходных азоторганических оснований происходило как по размеру молекул, так и по природе и содержанию функциональных групп.

На следующем этапе работы каждый из полученных элюатов подвергался более тонкому разделению методом тонкослойной хроматографии (ТСХ) на стандартных пластинках «Силуфол» (ЧССР) раз. мерами $15 \times 15$ см.

В данной статье рассмотрены структуры соединений гексанового и 
$\frac{\sqrt{3}}{3}$

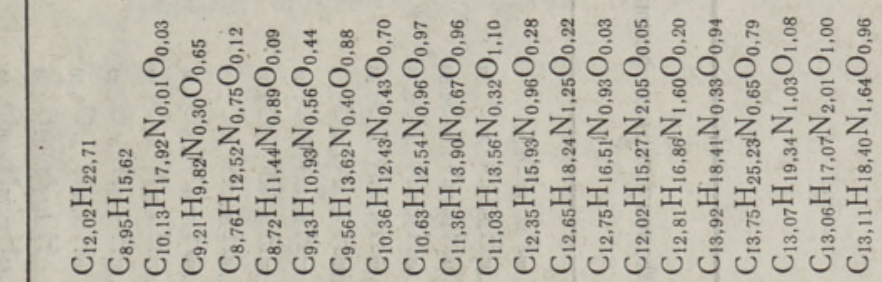

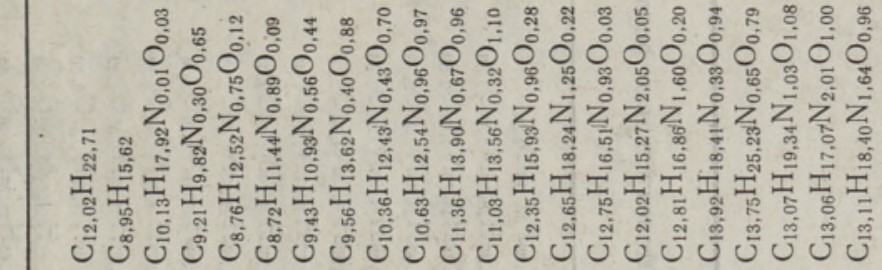

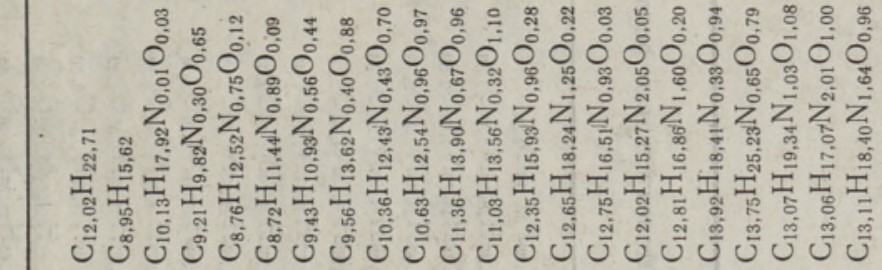

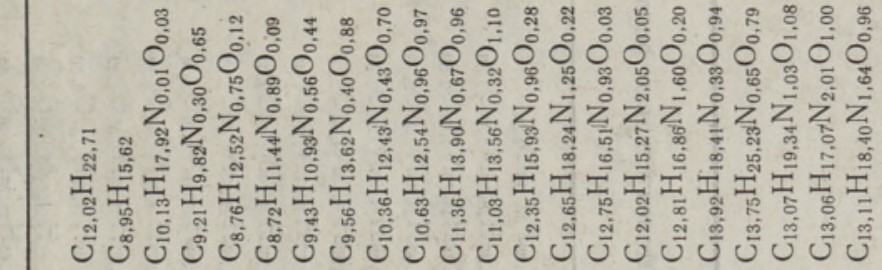

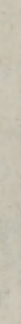

\begin{tabular}{|c|c|c|c|c|c|}
\hline 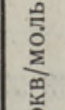 & $\hat{\theta}$ & 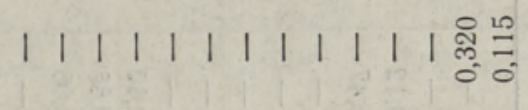 & & 1 & $\left|\begin{array}{l}\text { గ్ } \\
0\end{array}\right|$ \\
\hline 氶 & $0^{7}$ & 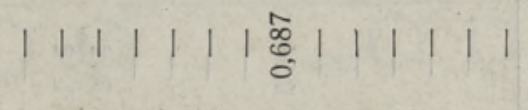 & & $\frac{9}{0}$ & 1111 \\
\hline 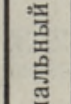 & $\underline{\square}$ & 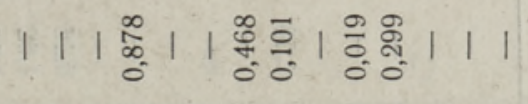 & 11 & L. & 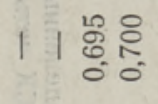 \\
\hline$\frac{\pi}{\theta}$ & 或 & 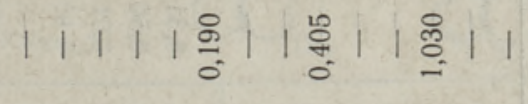 & 11 & $1 \stackrel{\infty}{0}$ & $\underset{0}{\frac{8}{0}} \frac{0}{0} \mid 1$ \\
\hline
\end{tabular}

¿

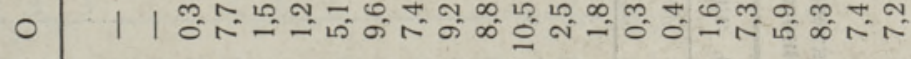

政

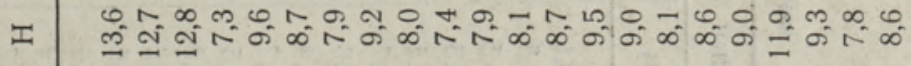

\#, $\infty, \infty$ เ

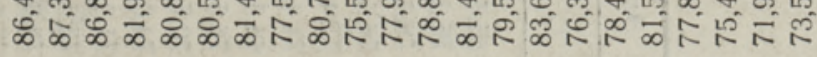

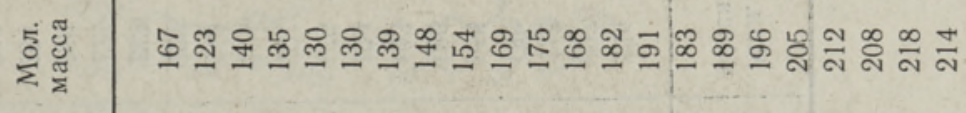

เป็

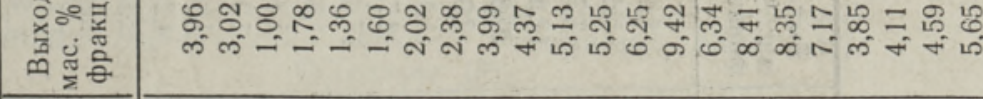

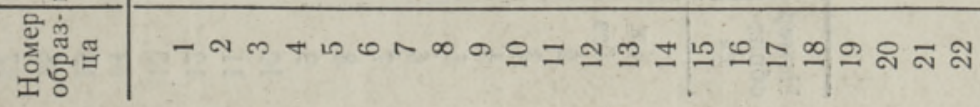




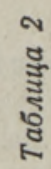

8

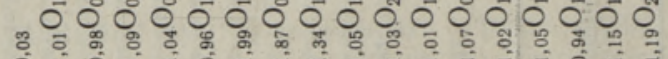

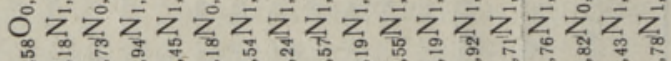

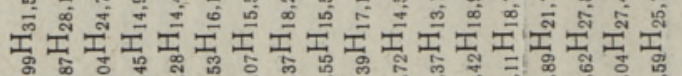
ษั่

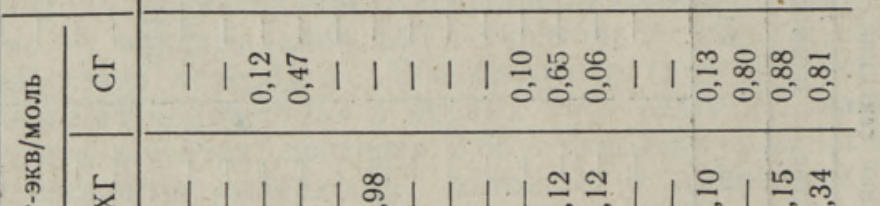

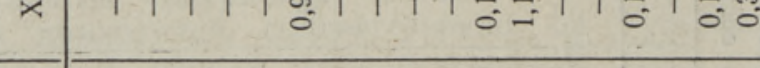

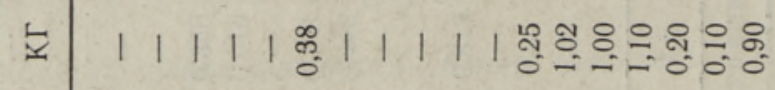

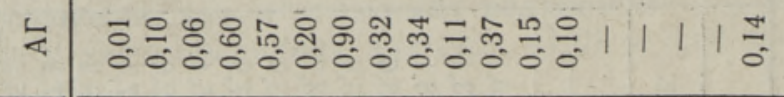

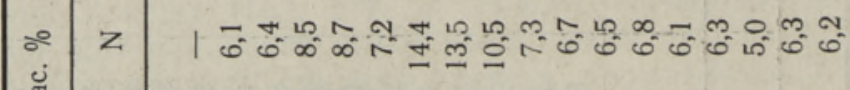

$\sum^{\frac{\pi}{2}} \longrightarrow$

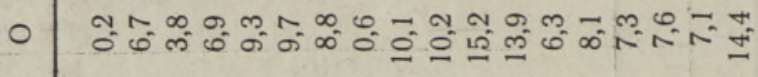

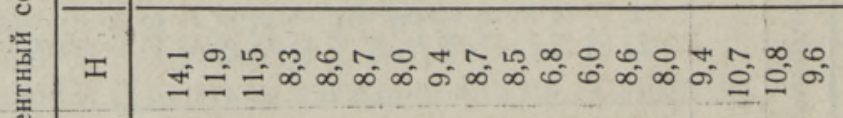

บ $\approx m m+\pi \infty$ m

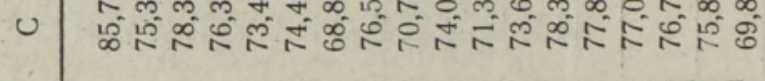

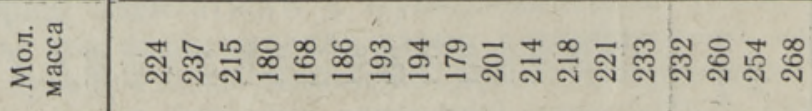

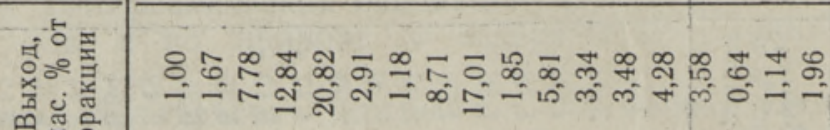

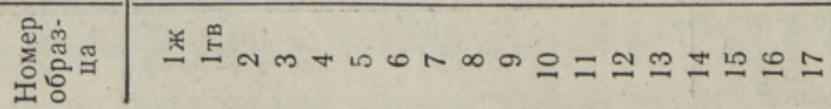


o<smiles>Cc1ccc2c(n1)CCOC2</smiles><smiles>CCCCNCc1ccccc1CN</smiles>

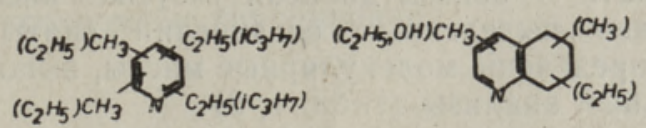

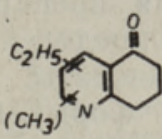

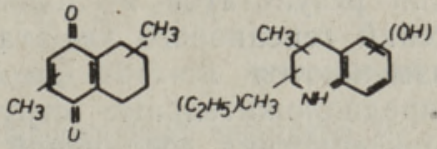<smiles>COc1ccccc1NC1CCCCC1</smiles>

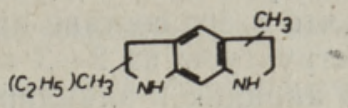

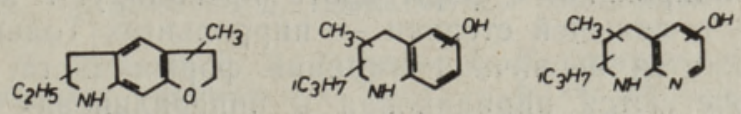<smiles>CCC1CCC([C@@H](O)C2CCC(C)CC2)CC1</smiles>

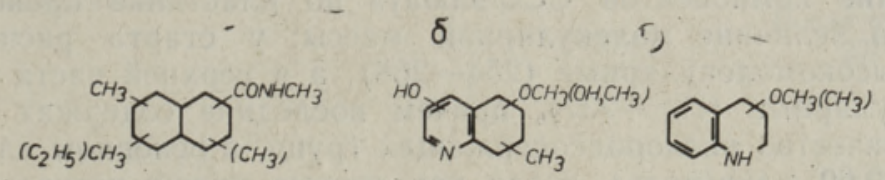

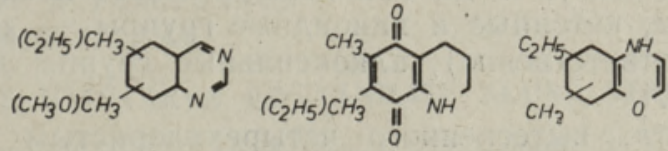

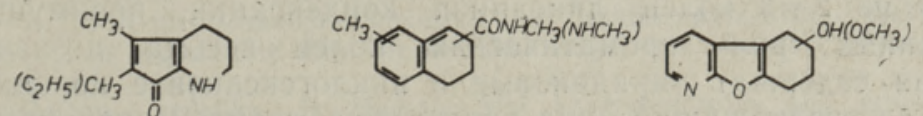<smiles>CCCCc1oc2ncccc2c(=O)c1CC</smiles><smiles>CCC1CCCC2OC3NCCCC3C(=O)C12</smiles><smiles>CCCC1CC2C(=O)C3CC(CC)C(C)CC3C2C1</smiles><smiles>CC12CNC3C(C1)C(=O)C1CCC(C)(CC13)C2</smiles><smiles>CC1CC2C(CC1(C)C)C1CC(C)(C)C2(C)C1</smiles><smiles>CC1CCC2NC3CC(O)CCC3C(=O)C2C1</smiles>

Рис. 2. Предположительные структурные формулы соединений первичных органических оснований: гексановый элюат $(a)$, $\mathrm{CCl}_{4}$-элюат (б). 
вытесненного с силикагеля четыреххлористым углеродом элюатов. Оптимальное разделение -достигалось́ при использовании систем:

а) для первого элюата - бензол:гексан:хлороформ:ацетон (25:22: $: 15: 2,5)$;

б) для второго элюата - бензол:диоксан:уксусная кислота (30:17:1). Для препаративно выделенных соединений сняты ИК-, УФ- и 'Н-ЯМР-спектры, определены молекулярные массы, выполнены элементный и функциональный анализы (табл. 1,2 ).

На основании результатов исследования для препаративно выделенных соединений гексанового элюата были определены молекулярные массы (изменяются от 123 до 218), выведены молекулярные (табл. 1) и предположительные структурные формулы (рис. 2, a). Подробная характеристика соединений гексанового элюата позволяет констатировать, что в его составе преобладают частично или полностыо гидрированные структуры из $2-3$ колец. Исключение составляют полиалкилированный пиридин и алкилированные бензиламины.

Из идентифицированных форм азота превалируют пиридиновые и пиперидиновые, в меньшей степени - пиррольные. Только в одной из структур содержится первичная аминная форма азота. В некоторых соединениях сочетаются пиридиновая и пиперидиновая формы.

Характерной особенностью гексанового элюата является наличие нескольких атомов азота и кислорода различных функциональных групп в составе одной молекулы. В целом из кислородсодержащих групп превалируют кетонные (как мостикового, так и циклического типа) и хиноидные.

Разделение компонентов $\mathrm{CCl}_{4}$-элюата по пластинке происходит в основном по величине молекулярной массы: у старта расположены наиболее высокомолекулярные $(254-268)$, а в верхней части - более низкомолекулярные $(168-237)$, причем последние содержат незначительное количество кислородсодержащих групп, в основном алкоксильных $(0,01-0,60$ г-экв/моль), тогда как первые имеют несколько форм кислорода (спиртовые, кетонные и хиноидные группы - до 0,$88 ; 1,10$ и 0,34 г-экв/моль соответственно), алкоксильные группы для них нехарактерны (табл. 2).

Соединения элюата, вытесненного четыреххлористым углеродом, построены из 2-3 колец линеарной конденсации, преимущественно гидрированных; роль ароматических колец весьма незначительна. Соединения содержат пиридиновые и циклогексановое кольца, гидрированный азотсодержащий цикл пиперидина, сконденсированный с ароматическим или хиноидным кольцом; пиримидиновый цикл с двумя атомами азота с гидрированным карбоциклом; гидрированный бензофурановый фрагмент, сочлененный с пиридиновым ядром, а также пиридиновый цикл, сопряженный с хромоновым (рис. $2, б)$.

Сравнение структур соединений, препаративно выделенных методом ТСХ, со структурами растительных алкалоидов $\left[{ }^{7,8}\right]$ указывает на аналогию между ними, на что обращено внимание в [ ${ }^{9}$. Нетрудно заметить сходство, например, соединения, имеющего пиридиновый цикл, сопряженный с фурановым и содержащим метоксильные группы (рис. $2, \sigma)$, со скиммиамином.

Хромоновый цикл, установленный в составе одного из компонентов рассматриваемого элюата, обнаружен во многих соединениях, выделенных из растительного материала, преимущественно пигментов. Пиримидиновый цикл идентифицирован в структуре вазицина (или пеганина).

Сходство отдельных структур элюата, вытесненного с силикагеля четыреххлористым углеродом, со структурой растительных алкалоидов позволяет использовать его для препаративного выделения отдель- 
ных соединений алкалоидоподобной структуры, которые после некоторых технологических операций могут быть рекомендованы в качестве ценных фармацевтических препаратов.

Второе направление применения - синтез красителей, поскольку некоторые из идентифицированных соединений содержат активные хромофорные и ауксохромные группировки.

\section{ЛИТЕРАТ УРА}

1. Платонов В. В. Исследование термохимических превращений углей Кузнецкого бассейна. Канд. дис. М., 1972.

2. Камнева А. И., Королев Ю. Г. Лабораторный практикум по химии топлива. М., 1975.

3. Черонис Н. Д., Ма Т. С. Макро- и полумикрометоды органического функционального анализа. М., 1973.

4. Глебко Н. М., Кочелева Л. П., Максимов О. Б. Функциональный анализ гуминовых кислот. - Хим. тверд. топл., 1970, № 2, 70-78.

5. Глебко H. М., Максимов О. Б. Новые методы исследования гуминовых кислот. Владивосток, 1972.

6. Безингер Н. Н., Гальперн Г. Д., Овечкина Т. И. Определение азота в нефтях и нефтепродуктах микрометодом Дюма. - В кн.: Методы анализа органических соединений нефти, их смесей и производных. М., 1960, 132-140.

7. Генри T. А. Химня растительных алкалондов. М., 1956.

8. Pictet, $H$. Ober Destillation der Steinkohle unter geringem Druck. - Chem. Ber., $1911,44,286$.

9. Кирнер В. Азот углей. - В кн.: Химия твердого топлива, I. М., 1951, 102-144.

Тульский государственный педагогический институт
Поступила в редакцию 17/II 1983

После переработки $23 / \mathrm{V} 1983$

V. PLATONOV, N. TABOLENKO,

O. KLJAVINA, L. IVLEVA

\section{KIVISÖE UTTETORVA ORGAANILISE ALUSE STRUKTUURI UURIMINE}

On uuritud ühendeid, mis moodustavad kivisöerühma $\Gamma 6$ uttetōrva orgaanilise aluse. IP-, UV- ja TMR-spektroskoopia, elemendi- ja funktsionaalanalüüsi teel saadud andmed näitavad, et orgaaniline alus on keerukas segu, mis sisaldab mitmesuguseid lämmastikuühendeid.

Adsorptsioon-, vedeliku- ja ōhukese kihi kromatograafia abil eraldatud puhtaid lämmastikku sisaldavaid orgaanilisi ühendeid uuriti kompleksselt füüsikalis-keemiliste ja keemiliste meetoditega.

On esitatud heksaani ja $\mathrm{CCl}_{4}$ eluaatide struktuurivalemid.

V. PLATONOV, N. TABOLENKO,

O. KLYAVINA, L. IVLEVA

\section{INVESTIGATION OF THE STRUCTURE OF THE ORGANIC BASES OF PRIMARY COAL TARS}

By the IR-, UV-, NMR-spectroscopy, routine and functional analyses and cryoscopy it was shown that the organic bases consist of a hydrogenated aromatic or heterocyclic nucleus with nitrogen-containing compounds and mostly with phenol, chinoid, ketone or other groups.

Some pure nitrogen-containing organic compounds were isolated by liquid column and preparative thin-layer chromatography.

The compounds obtained were investigated with the help of chemical and physicochemical methods. The structural formulas of hexane- and $\mathrm{CCl}_{4}$-eluate compounds were suggested. 